\title{
ACOUSTIC RADIATION FORCE IMPULSE IS EQUIVALENT TO LIVER BIOPSY TO EVALUATE LIVER FIBROSIS IN PATIENTS WITH CHRONIC HEPATITIS C AND NONALCOHOLIC FATTY LIVER DISEASE
}

\author{
Juliana Ayres de Alencar Arrais GUERRA ${ }^{1}$, Marcus TRIPPIA ${ }^{2}$, Alcindo PISSAIA JUNIOR ${ }^{1}$, \\ Bernardo Corrêa de Almeida TEIXEIRA ${ }^{2}$ and Cláudia Alexandra Pontes IVANTES ${ }^{1}$
}

Received 8/1/2015 Accepted 6/3/2015

ABSTRACT - Background - Liver biopsy is recommended as the gold standard method for assessing the stage of liver fibrosis in patients with chronic liver disease. However, it is invasive, with potential risks and complications. Elastography is an ultrasound technique that provides information of changes in the liver tissue, evaluating tissue elasticity and acoustic radiation force impulse is one of the available techniques. Objective - The main objective of this study was to evaluate the sensitivity and specificity of acoustic radiation force impulse comparing to liver biopsy to evaluate fibrosis in patients with chronic hepatitis $\mathrm{C}$ virus and nonalcoholic fatty liver disease. Methods - Twenty four patients were included, everyone underwent liver biopsy and acoustic radiation force impulse, and the results were compared with values described in the literature by several authors. Results - In the population of patients with chronic hepatitis C, our data were better correlated with data published by Carmen Fierbinteanu-Braticevici et al., with an accuracy of $82.4 \%$, sensitivity of $71.4 \%$ and specificity of $90 \%$. For nonalcoholic fatty liver disease, our data were better correlated with data published by Masato Yoneda et al., with an accuracy of $85.7 \%$, sensitivity $80 \%$ and specificity of $100 \%$. Conclusion - Acoustic radiation force impulse is a method with good accuracy to distinguish initial fibrosis from advanced fibrosis in hepatitis $\mathrm{C}$ virus and nonalcoholic fatty liver disease and can replace biopsy in most cases.

HEADINGS - Liver Cirrhosis. Non-alcoholic fatty liver disease. Elasticity imaging techniques. Chronic hepatitis C.

\section{INTRODUCTION}

Liver biopsy is recommended as the gold standard for assessing the stage of liver fibrosis in patients with chronic liver disease ${ }^{(21)}$. However, it is invasive, with potential risks and complications ${ }^{(5)}$. Approximately $1 \%-3 \%$ of patients require hospitalization because of complications, including severe events. A quarter of patients report pain after the procedure. In addition, the diagnostic accuracy of biopsy defining hepatic fibrosis is influenced by the quality of the sample, and there may be discrepancies intra- and inter-observer at about $10 \%-20 \%{ }^{(18,21,22)}$. The risk of death due to complications of liver biopsy is $0.03 \%{ }^{(2)}$. Thus, arises the need for noninvasive methods for assessing the degree of fibrosis in liver diseases.
Elastography is an ultrasound technique that provides information about changes in the liver tissue, evaluating tissue elasticity. The Acoustic Radiation Force Impulse (ARFI), one of the available techniques, defines liver fibrosis through the emission of short acoustic pulses of high intensity, at a fixed frequency, in tissue points defined by the operator, while conventional ultrasound is used to access the tissue elasticity, evaluating mechanical response $\mathrm{e}^{(3,6,11,16)}$. The method analyzes a rectangular area of liver, measuring $1 \times 0.5 \mathrm{~cm}$, in a variable depth ${ }^{(14)}$. The speed of wave propagation in the evaluated area is proportional to tissue elasticity, in other words, the more fibrosis, the more increased is the speed. The result is expressed in meters per second $(\mathrm{m} / \mathrm{s})^{(19)}$. Thus, the ARFI method has some advantages: it is

Declared conflict of interest of all authors: none

Disclosure of funding: no funding received

Unidade de Gastroenterologia e Hepatologia, Hospital Nossa Senhora das Graças, Curitiba, PR; ${ }^{2}$ Diagnóstico Avançado por Imagem (DAPI), Curitiba, PR. Brasil. Correspondence: Cláudia Ivantes. Hospital Nossa Senhora das Graças - Gastroenterologia e Hepatologia. Rua Ari José Valle 1200, casa 13. Bairro São João. CEP. 82030-000 - Curitiba, PR, Brasil. E-mail: claudiaivantes@gmail.com 
well tolerated and non-invasive, fast, employs conventional ultrasound machine, has low cost and can be done even in obese and/or patients with ascites ${ }^{(20)}$.

This study aims assess the sensitivity and specificity of ARFI compared to liver biopsy to quantify hepatic fibrosis in patients with hepatitis $\mathrm{C}$ virus (HCV) and nonalcoholic fatty liver disease (NAFLD), establish the best author to be used as a reference in our population with HCV and NAFLD and define the best cutoff of ARFI in $\mathrm{m} / \mathrm{s}$, to differentiate initial from advanced fibrosis.

\section{METHODS}

The study included males and females patients between 18 and 75 years old, any race, with chronic viral hepatitis $\mathrm{C}$ or NAFLD, who have undergone liver biopsy in an interval of 8 months from ARFI performance. Patients were accompanied and treated in our service from January 2012 to May 2014.

Liver biopsies were performed in two different services, through needle aspiration guided by ultrasound. The fragments were stained with Giemsa and fibrosis evaluation was performed by a single pathologist. The biopsy report was based on the METAVIR system, which classifies hepatic fibrosis in FO (no fibrosis), F1 (portal and periportal fibrosis without septa), F2 (portal and periportal fibrosis, with scarce fibrotic septa), F3 (portal and periportal fibrosis with numerous fibrotic septa) and F4 (nodules of fibrosis/ cirrhosis). Patients who had liver fragments with less than 7 portal spaces were excluded from the study.

For ARFI realization, the patient was in left lateral decubitus position, and the ultrasound transducer was positioned on the 8th or 9th intercostal space. Patients should be in apnea, without any liver movement. Ten measurements were performed and the average was obtained, with sampling $10 \mathrm{~mm}$ under liver capsule.

The results obtained with the ARFI (in $\mathrm{m} / \mathrm{s}$ ) were compared with values previously published in the literature by various authors in order to establish the degree of hepatic fibrosis (Tables 1 and 2).

The quantitative variables were described as mean, median, minimum and maximum values and standard deviations. For qualitative variables, the results of frequencies and percentages were presented. For comparison of two groups, according to fibrosis classification in relation to the ARFI outcome, t-student test was used, for independents samples. To determinate a cutoff for ARFI, considering liver biopsy as the gold standard result, a ROC curve was adjusted. Quality evaluation of ARFI in determining the degree of fibrosis was done by estimating values of sensitivity, specificity and accuracy. For statistical tests, $P$ values $<0.05$ were considered statistically significant. Data were analyzed with the computer program SPSS Statistics v.20.

TABLE 1. Association between shear wave velocities determined by acoustic radiation force impulse elastography (in m/s) and METAVIR score for viral chronic hepatitis $\mathrm{C}$ (VHC), according to different authors

\begin{tabular}{|c|c|c|c|c|c|c|}
\hline \multirow{2}{*}{ Author (reference) } & \multicolumn{5}{|c|}{ METAVIR score } & \multirow{2}{*}{$\mathbf{N}$} \\
\hline & F0 & F1 & F2 & F3 & F4 & \\
\hline \multicolumn{7}{|l|}{ Monica Lupsor ${ }^{(12)}$} \\
\hline $\operatorname{ARFI}(\mathrm{m} / \mathrm{s})$ & $<1.19$ & $1.19-1.34$ & $1.34-1.61$ & $1.61-2$ & $>2$ & 112 \\
\hline \multicolumn{7}{|c|}{ Mireen Friedrich-Rust ${ }^{(8)}$} \\
\hline $\operatorname{ARFI}(\mathrm{m} / \mathrm{s})$ & $<1.16$ & $1.16-1.34$ & $1.34-1.75$ & $1.75-2.38$ & $>2.38$ & 81 \\
\hline \multicolumn{7}{|c|}{ Fierbinteanu-Braticevici ${ }^{(5)}$} \\
\hline $\operatorname{ARFI}(\mathrm{m} / \mathrm{s})$ & $<1.185$ & $1.185-1.215$ & $1.215-1.54$ & $1.54-1.94$ & $>1.94$ & 74 \\
\hline \multicolumn{7}{|l|}{$\operatorname{Rizzo}^{(15)}$} \\
\hline $\operatorname{ARFI}(\mathrm{m} / \mathrm{s})$ & $<1.31$ & $1.31-1.45$ & $1.45-1.99$ & $1.99-2.34$ & $>2.34$ & 139 \\
\hline \multicolumn{7}{|l|}{ Ioan Sporea ${ }^{(17)}$} \\
\hline $\operatorname{ARFI}(\mathrm{m} / \mathrm{s})$ & $<1.19$ & $1.19-1.33$ & $1.33-1.43$ & $1.43-1.55$ & $>1.55$ & 914 \\
\hline
\end{tabular}

FO: no fibrosis; F1: portal and periportal fibrosis without septa; F2: portal and periportal fibrosis, with scarce fibrotic septa; F3: portal and periportal fibrosis with numerous fibrotic septa; F4: nodules of fibrosis/cirrhosis. ARFI: acoustic radiation force impulse.

TABLE 2. Association between shear wave velocities determined by acoustic radiation force impulse elastography (in m/s) and METAVIR score for nonalcoholic fatty liver disease (NAFLD), according to different authors

\begin{tabular}{|c|c|c|c|c|c|c|}
\hline \multirow{2}{*}{ Author (reference) } & \multicolumn{5}{|c|}{ METAVIR score } & \multirow{2}{*}{$\mathbf{N}$} \\
\hline & F0 & F1 & F2 & F3 & F4 & \\
\hline \multicolumn{7}{|l|}{ Masato Yoneda ${ }^{(22)}$} \\
\hline $\operatorname{ARFI}(\mathrm{m} / \mathrm{s})$ & $<1.12$ & $1.12-1.13$ & $1.13-1.78$ & $1.78-2.18$ & $>2.18$ & 54 \\
\hline \multicolumn{7}{|l|}{ Akihiko Osaki $^{(13)}$} \\
\hline $\operatorname{ARFI}(\mathrm{m} / \mathrm{s})$ & $<1.34$ & $1.34-1.79$ & $1.79-2.2$ & $2.2-2.9$ & $>2.9$ & 26 \\
\hline
\end{tabular}

FO: no fibrosis; F1: portal and periportal fibrosis without septa; F2: portal and periportal fibrosis, with scarce fibrotic septa; F3: portal and periportal fibrosis with numerous fibrotic septa; F4: nodules of fibrosis/cirrhosis. ARFI: acoustic radiation force impulse. 


\section{RESULTS}

It was enrolled 24 patients in this study, thirteen females and 11 males. Ages ranged between 34 and 70 years old, with mean of 51.4 years. Seventeen patients had VHC and seven had NAFLD as the etiology of liver disease (Table 3). ARFI

TABLE 3. Characteristics of patients with chronic liver disease

\begin{tabular}{lc}
\hline $\mathbf{N}$ & 24 \\
\hline Age & \\
Mean & 51.4 years \\
Median & 49.5 years \\
Gender & \\
Female & $13(54.2 \%)$ \\
Male & $11(45.8 \%)$ \\
Etiology of liver disease & \\
HCV & $17(70.8 \%)$ \\
$\quad$ NAFLD & $7(29.2 \%)$ \\
\hline
\end{tabular}

elastography was performed for all subjects and share wave velocity was successfully measured in all subjects. The maximum and mean interval between liver biopsy and the realization of ARFI elastography was 8 and 1.3 months, respectively.

The result of liver biopsy using METAVIR score classified five patients as F0, one as F1, six as F2, eleven as F3 and one as F4. For better statistical evaluation, patients were divided into two groups: early fibrosis FO, F1 and F2 (12 patients) and advanced fibrosis F3 and F4 (12 patients).

In the tables below are presented the performance of ARFI elastography results from the patients enrolled in this study expressed by shear wave velocity in evaluation of different stages of liver fibrosis (METAVIR score), grouped into initial (F0, F1 and F2) and advanced fibrosis (F3 and F4) and related to different authors for specific liver disease (Tables 4 and 5). To interpret the results, the share wave velocity value obtained with ARFI elastography was correlated to the degree of fibrosis from different authors and then the value obtained from fibrosis, compared to liver biopsy. If a patient with $\mathrm{HCV}$ in this study had $1.20 \mathrm{~m} / \mathrm{s}$ as a share wave velocity,

TABLE 4. Performance of acoustic radiation force impulse elastography (ARFI) for the assessment of histological fibrosis stage in patients with chronic hepatitis $C$ based on different authors

\begin{tabular}{|c|c|c|c|c|c|}
\hline \multirow{2}{*}{ ARFI classification by author } & \multicolumn{2}{|c|}{ METAVIR score } & \multirow{2}{*}{$\begin{array}{c}\text { Sensitivity } \\
\%\end{array}$} & \multirow{2}{*}{$\begin{array}{c}\text { Specificity } \\
\%\end{array}$} & \multirow{2}{*}{$\begin{array}{c}\text { Accuracy } \\
\%\end{array}$} \\
\hline & $\mathrm{F} 0, \mathrm{~F} 1$ and $\mathrm{F} 2(\%)$ & $\mathrm{F} 3$ and $\mathrm{F} 4(\%)$ & & & \\
\hline \multicolumn{6}{|l|}{ Monica Lupsor $^{(12)}$} \\
\hline $\mathrm{F} 0, \mathrm{~F} 1$ and $\mathrm{F} 2$ & $9(90)$ & $3(42.86)$ & 57.1 & 90 & 76.5 \\
\hline $\mathrm{F} 3$ and $\mathrm{F} 4$ & $1(10)$ & $4(57.14)$ & & & \\
\hline \multicolumn{6}{|l|}{ Mireen Friedrich-Rust ${ }^{(8)}$} \\
\hline F0, F1 and F2 & $10(100)$ & $3(42.86)$ & 57.1 & 100 & 82.4 \\
\hline $\mathrm{F} 3$ and $\mathrm{F} 4$ & $0(0)$ & $4(57.14)$ & & & \\
\hline \multicolumn{6}{|l|}{ Fierbinteanu-Braticevici $C^{(5)}$} \\
\hline $\mathrm{F} 0, \mathrm{~F} 1$ and $\mathrm{F} 2$ & $9(90)$ & $2(28.57)$ & 71.4 & 90 & 82.4 \\
\hline $\mathrm{F} 3$ and $\mathrm{F} 4$ & $1(10)$ & $5(71.43)$ & & & \\
\hline \multicolumn{6}{|l|}{$\operatorname{Rizzo}^{(15)}$} \\
\hline $\mathrm{F} 0, \mathrm{~F} 1$ and $\mathrm{F} 2$ & $10(100)$ & $4(57.14)$ & 42.9 & 100 & 76.5 \\
\hline $\mathrm{F} 3$ and $\mathrm{F} 4$ & $0(0)$ & $3(42.86)$ & & & \\
\hline \multicolumn{6}{|l|}{ Ioan Sporea $^{(17)}$} \\
\hline $\mathrm{F} 0, \mathrm{~F} 1$ and $\mathrm{F} 2$ & $7(70)$ & $2(28.57)$ & 71.4 & 70 & 70.6 \\
\hline $\mathrm{F} 3$ and $\mathrm{F} 4$ & $3(30)$ & $5(71.43)$ & & & \\
\hline
\end{tabular}

TABLE 5. Performance of acoustic radiation force impulse elastography (ARFI) for the assessment of histological fibrosis stage in patients with nonalcoholic fatty liver disease (NAFLD) based on different authors

\begin{tabular}{|c|c|c|c|c|c|}
\hline \multirow{2}{*}{ ARFI classification by author } & \multicolumn{2}{|c|}{ Biopsy } & \multirow{2}{*}{$\begin{array}{c}\text { Sensitivity } \\
\%\end{array}$} & \multirow{2}{*}{$\begin{array}{c}\text { Specificity } \\
\%\end{array}$} & \multirow{2}{*}{$\underset{\%}{\text { Accuracy }}$} \\
\hline & $\mathrm{F} 0, \mathrm{~F} 1$ and $\mathrm{F} 2(\%)$ & $\mathrm{F} 3$ and $\mathrm{F} 4(\%)$ & & & \\
\hline \multicolumn{6}{|l|}{ Masato Yoneda ${ }^{(22)}$} \\
\hline $\mathrm{F} 3$ and $\mathrm{F} 4$ & $0(0)$ & $4(80)$ & & & \\
\hline \multicolumn{6}{|l|}{ Akihiko Osaki ${ }^{(13)}$} \\
\hline
\end{tabular}


when we compare this result with the results from author Monica Lupsor ${ }^{(12)}$, the patient would be classified as F1 and when compared with Rizzo ${ }^{(15)}$ would be classified as F0. Table 6 shows descriptive statistics from ARFI elastography in $\mathrm{m} / \mathrm{s}$, according to METAVIR score. The results indicated significant difference between patients with initial fibrosis ( F0, F1 and F2) and patients with advanced fibrosis (F3 and F4), according to the results of ARFI elastography $(P=0.004)$ (Figure 1). A ROC curve was adjusted to values of ARFI, considering liver fibrosis classifications by biopsy. The area under the curve was $0.889(P=0.001)$, with statistical significance, indicating that ARFI was able to discriminate initial fibrosis from advanced fibrosis (Figure 2). However, values between $1.09 \mathrm{~m} / \mathrm{s}$ and 1.70 $\mathrm{m} / \mathrm{s}$ are in the so called "gray zone", in which overlapping of ARFI values for fibrosis occurs, not being possible to differentiate between initial and advanced fibrosis.

The optimal cutoff value of ARFI elastography for differentiated advanced fibrosis from initial fibrosis was 1.535 $\mathrm{m} / \mathrm{s}$ with $83.3 \%$ sensitivity and $91.7 \%$ specificity.

\section{DISCUSSION}

In chronic viral hepatitis, information of the degree of liver fibrosis is essential for defining the treatment time and the best drug to be employed, while in the NAFLD, the fibrosis may indicate a higher risk of progression to liver cirrhosis. Therefore, knowing hepatic fibrosis is an extremely important point in the hepatologist clinical practice ${ }^{(1)}$.
In Brazil, the need for biopsy to treat hepatitis $\mathrm{C}$ can delay or even prevent the onset of antiviral therapy. This difficulty occurs due to the heterogeneity of medical care, few referral services and few trained doctors to biopsy. In NAFLD, due to the high prevalence, it is impossible to biopsy all cases. Therefore, more than ever, dissemination and validation of non-invasive methods is of paramount importance.

The ideal noninvasive method should have sufficient sensitivity to discriminate between different stages of fibrosis, ability to correlate with dynamic changes in the progression or regression of fibrosis, capacity to predict clinical outcomes, assess fibrosis in any etiology of liver disease, good reproducibility, accessibility, low cost and results in real time. This method does not exist yet.

ARFI elastography technique, the method employed in this study, was able to discriminate between initial and advanced fibrosis with results in real time. This method coupled with conventional ultrasonography also provides anatomical information in screening hepatocellular carcinoma and portal hypertension diagnosis.

To further improve the accuracy of ARFI, it is still possible associate it with other noninvasive methods, such as Fib-4 and FibroTest.

In the present study, we compared liver biopsy METAVIR score with ARFI elastography. In the population of patients with chronic hepatitis $\mathrm{C}$, our best data correlated with data published by Fierbinteanu-Braticevici et al..$^{(5)}$, with $82.4 \%$ accuracy, $71.4 \%$ sensitivity and $90 \%$ specificity. For NAFLD,

TABLE 6. Descriptive values of acoustic radiation force (ARFI) impulse (m/s) compared to liver biopsy in patients with chronic hepatitis $\mathrm{C}$ and nonalcoholic fatty liver disease (NAFLD)

\begin{tabular}{lcccccc}
\hline \multirow{2}{*}{ Fibrosis stage METAVIR } & \multicolumn{7}{c}{ ARFI (m/s) } \\
\cline { 2 - 7 } & $\mathrm{n}$ & Mean & Median & Minimum & Maximum & Standard deviation \\
\hline F0, F1 and F2 & 12 & 1.28 & 1.23 & 0.98 & 1.70 & 0.21 \\
F3 and F4 & 12 & 2.32 & 1.99 & 1.09 & 3.96 & 1.00 \\
\hline
\end{tabular}

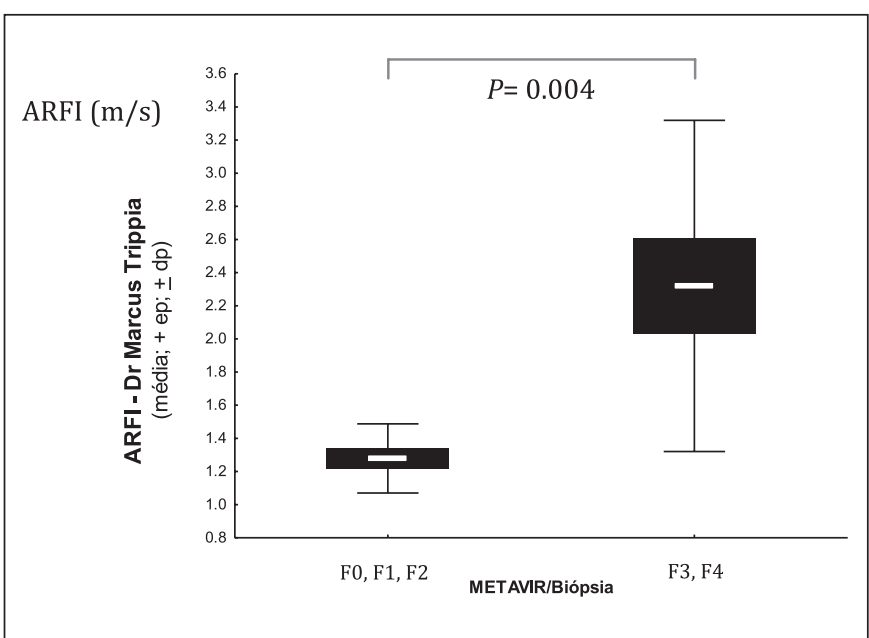

FIGURE 1. Liver stiffness expressed by shear wave velocity and histological stage. Box plots show median values with standard deviation of shear wave velocity determined by ARFI elastography.

ARFI, acoustic radiation force impulse.

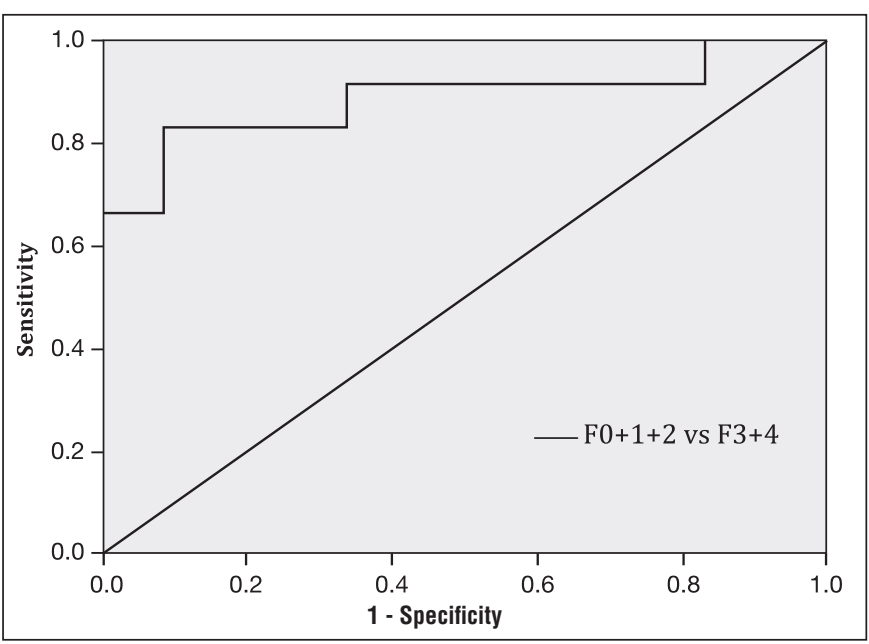

FIGURE 2. Receiver-operating characteristics curves of liver stiffness determined by ARFI elastography for de diagnosis of advanced fibrosis $(\mathrm{F} 0+1+2$ vs $\mathrm{F} 3+4)$.

ARFI, acoustic radiation force impulse. 
we obtained better results with data published by Masato Yoneda et al. ${ }^{(22)}$, with $85.7 \%$ accuracy, $80 \%$ sensitivity and $100 \%$ specificity.

Our analysis defined the ARFI elastography cutoff value with better sensitivity and specificity for liver fibrosis $\geq 3$ as $1.53 \mathrm{~m} / \mathrm{s}$, while the author Lupsor et al. ${ }^{(12)}$ found the cutoff value $1.61 \mathrm{~m} / \mathrm{s}$. ARFI values between $1.09 \mathrm{~m} / \mathrm{s}$ and $1.70 \mathrm{~m} / \mathrm{s}$ are not able to differentiate between initial and advanced fibrosis. In this case, it is suggested to proceed with liver biopsy to determine degree of liver fibrosis.

It must be observed the importance of separating patients according etiology from liver disease to interpreted ARFI elastography results, since the shear wave velocity changes with the elasticity of the hepatic parenchyma, and this may be different within etiologies $(4,7,9,10,12,13,15,17,19)$. Therefore, it is justified separated analysis, as done in this study.

In conclusion, this study has demonstrated that ARFI elastography technique is a novel, non-invasive method with good accuracy to differentiate initial from advanced liver fibrosis in patients with $\mathrm{HCV}$ and NAFLD, and may replace liver biopsy in the great majority of the cases.

\section{Authors' contributions}

Guerra JAAA: data collection, statistical analysis and paper writing. Trippia M: elastography execution and liver biopsy. Pissaia Jr A: patient inclusion. Teixeira BCA: elastography execution. Ivantes CAP: patient inclusion, orientation and coordination in all phases of the research.

Guerra JAAA, Trippia M, Pissaia Jr A, Teixeira BCA, Ivantes CAP. Exame de sonoelastografia é equivalente a biópsia hepática na análise de fibrose em pacientes portadores de hepatite $\mathrm{C}$ crônica e doença hepática gordurosa não alcoólica. Arq Gastroenterol. 2015,52(3):234-8.

RESUMO - Contexto - A biópsia hepática é considerada padrão-ouro para definição de fibrose hepática em pacientes com doença hepática crônica. No entanto, é um método invasivo, com potenciais riscos e complicações. A elastografia é uma técnica de ultrassonografia que fornece informações sobre variações no tecido hepático, avaliando elasticidade tecidual e sonoelastografia é uma das técnicas disponíveis. Objetivo - O principal objetivo do estudo é avaliar a sensibilidade e especificidade da sonoelastografia comparada a biópsia hepática para análise do grau de fibrose hepática em pacientes com hepatite C crônica e doença hepática gordurosa não alcoólica. Métodos - Vinte e quatro pacientes foram incluídos no estudo, submetidos a biópsia hepática e sonoelastografia. Os resultados obtidos foram comparados a valores descritos na literatura por diferentes autores. Resultados - Na população de pacientes com hepatite $\mathrm{C}$ crônica, os dados melhor se correlacionaram com resultados publicados por Carmen Fierbinteanu-Braticevici e col, com uma acurácia de $82,4 \%$, sensibilidade de $71,4 \%$ e especificidade de $90 \%$. Para doença hepática gordurosa não alcoólica, a melhor correlação se deu com dados publicados por Masato Yoneda e col, com acurácia de $85,7 \%$, sensibilidade de $80 \%$ e especificidade de $100 \%$. Conclusão - Sonoelastografia é um método com boa acurácia para diferenciar fibrose avançada de fibrose inicial e pode substituir a biópsia hepática na maioria das vezes.

DESCRITORES - Cirrose hepática. Hepatopatia gordurosa não alcoólica. Técnicas de imagem por elasticidade. Hepatite C Crônica.

\section{REFERENCES}

1. Adebajo C, Talwalkar J, Poterucha J, Kim W, Charlton M. Ultrasound-Based Transient Elastography for the Detection of Hepatic Fibrosis in Patients with Recurrent Hepatitis C Virus After Liver Transplantation: a Systematic Review and Meta-Analysis. Liver Transplant. 2012;18(3):323-31

2. Bayard M, Holt J, Boroughs E. Nonalcoholic Fatty Liver Disease. Am. Fam. Physician. 2006;73(11):1961-8.

3. Bota S, Herkner H, Sporea I, Salzl P, Sirli R, Neghina A, et al. Meta-analysis: ARFI elastography versus transient elastography for the evaluation of liver fibrosis. Liver Int. 2013;33(8):1138-47.

4. Castera L. Noninvasive Methods to Assess Liver Disease in Patients With Hepatitis B or C. Gastroenterology. 2012;142(6):1293-302.

5. Fierbinteanu-Braticevici C, Andronescu D, Usvat R, Cretoiu D, Baicus C, Marinoschi $\mathrm{G}$. Acoustic radiation force imaging sonoelastography for noninvasive staging of liver fibrosis. World J Gastroenterol. 2009;15(44):5525-32.

6. Friedrich-Rust M, Nierhoff J, Lupsor M, Sporea I, Fierbinteanu-Braticevici C Strobel D, et al. Performance of Acoustic Radiation Force Impulse imaging for the staging of liver fibrosis: a pooled meta-analysis. J. Viral Hepatitis. 2012;19(2):e212-9.

7. Friedrich-Rust M, Romen D, Vermehren J, Kriener S, Sadet D, Herrmann E, et al. Acoustic radiation force impulse-imaging and transient elastography for non-invasive assessment of liver fibrosis and steatosis in NAFLD. Eur. J. Radiol. 2012;81(3):e325-31.

8. Friedrich-Rust M, Wunder K, Kriener S, Sotoudeh F, Richter S, Bojunga J, et al Liver Fibrosis in Viral Hepatitis: Noninvasive Assesment with Acoustic Radiation Force Impulse Imaging versus Transient Elastography. Radiology. 2009;252(2):595604.

9. Ganne-Carrié N, Ziol M, Ledinghen V, Douvin C, Marcellin P, Castera L, et al Accuracy of Liver Stiffness Measurement for the Diagnosis of Cirrhosis in Patient With Chronic Liver Diseases. Hepatology. 2006;44(6):1511-7.

10. Goertz R, Zopf Y, Jugl V, Heide R, Janson C, Strobel D, et al. Measurement of Liver Elasticity with Acoustic Radiation Force Impulse (ARFI) Technology: An Alternative Noninvasive Method for Staging Liver Fibrosis in Viral Hepatitis. Ultraschall in Med. 2010;31(2):151-5

11. Haque M, Robinson C, Owen D, Yoshida E, Harris A. Comparison of acoustic radiation force impulse imaging (ARFI) to liver biopsy histologic scores in the evaluation of chronic liver disease: a pilot study. Annals Hepatol. 2010;9(3):289-93.
12. Lupsor M, Badea R, Stefanescu H, Sparchez Z, Branda H, Serban A, et al. Performance of a New Elastographic Method (ARFI technology) Compared to Unidimensional Transient Elastography in the Noninvasive Assessment of Chronic Hepatitis C. Preliminary Results. J Gastrointestin Liver Dis. 2009;18(3): 303-10.

13. Osaki A, Kubota T, Suda T, Igarashi M, Nagasaki K, Tsuchiya A, et al. Shear wave velocity is a useful marker for managing nonalcoholic steatohepatitis. World J Gastroenterol. 2010;16(23):2918-25.

14. Rifai K, Cornberg J, Mederacke I, Bahr M, Wedemeyer H, Malinski P, et al Clinical Feasibility of liver elastography by acoustic radiation force impulse imaging. Dig. Liver Dis. 2011;43(6):491-7.

15. Rizzo L, Calvaruso V, Cacopardo B, Alessi N, Attanasio M, Petta S, et al. Comparison of Transient Elastography and Acoustic Radiation Force Impulse for Non-invasive Staging of Liver Fibrosis in Patients With Chronic Hepatitis C Am. J. Gastroenterol. 2011;106:2112-20.

16. Sporea I, Badea R, Sirli R, Lupsor M, Popescu A, Danila M, et al. How eficiente is acoustic radiation force impulse elastography for the evaluation of liver stiffness? Hepat Mon. 2011;11(7):532-8.

17. Sporea I, Bota S, Peck-Radosavljevic M, Sirli R, Tanaka H, Iijima H, et al. Acoustic Radiation Force impulse Elastography for fibrosis evaluation in patients with chronic hepatites C: An international multicenter study. Eur. J. Radiol. 2012 81(12):4112-8

18. Sporea I, Gilja O, Bota S, Sirli R, Popescu A. Liver Elastography - An Update Med Ultrason. 2013;15(4):304-14.

19. Sporea I, Sirli R, Deleanu A, Popescu A, Focsa M, Danila M, et al. Acoustic Radiation Force Impulse Elastography as Compared to Transient Elastography and Liver Biopsy in Patients with Chronic Hepatopathies. Ultraschall in Med 2011;32(Suppl 1):S46-52.

20. Sporea I, Sirli R, Popescu A, Danila M. Acoustic Radiation Force Impulse (ARFI) - a new modality for the evaluation of liver fibrosis. Med Ultrasonography. 2010;12(1):26-31

21. Takahashi H, Ono N, Eguchi Y, Eguchi T, Kitajima Y, Kawaguchi Y, et al. Evaluation of acoustic radiation force impulse elastography for fibrosis staging of chronic liver disease: a pilot study. Liver Int. 2010;30(4):538-45.

22. Yoneda M, Suzuki K, Kato S, Fujita K, Nozaki Y, Hosono K, et al. Nonalcoholic Fatty Liver Disease: US-based Acoustic Radiation Force Impulse Elastography. Radiology. 2010;256(2):640-7. 